\title{
CONTEXTO: CONSIDERANDO AD INFINITUM
}

\author{
(Context: concerning ad 'infinitum')
}

\author{
Claudiana Nogueira de Alencar ${ }^{1}$ \\ Dina Maria Martins Ferreira ${ }^{2}$ \\ (Universidade Estadual do Ceará -UECE)
}

\begin{abstract}
Parece evidente que o campo de equivocidade da palavra "comunicação" se deixa maciçamente reduzir pelos limites do que se chama noção de contexto.
\end{abstract}

(Derrida, 1991: 350)

\begin{abstract}
This study aims to deconstruct the limits of conceptual context. We start from Systemic Functional Linguistics (LFS) of Halliday (1970, 1978), which does not cease to score in Critical Discourse Analysis (ADC) (Fairclough, 2001), and we use them for voices of philosophy of language (Wittgenstein, 1989) and pragmatics (Austin, 1962), whose interfaces move in the counterflow of dualisms between the semantic dimension as abstract-formal and the pragmatic dimension as an empirical context. And a road of argument, we get the impossibility of establishing conceptual categorizations (Rajagopalan, forthcoming), due to the fluidity in the sense of context falls.
\end{abstract}

Keywords: contexto; interfaces; conceptual fluidity

1 Claudiana Nogueira de Alencar é professora, pesquisadora e coordenadora do Programa de Pós-Graduação em Linguística Aplicada, Universidade Estadual do Ceará/UECE; pós-doutora (2010) e doutora (2005) pelo Instituto de Estudos da Linguagem/Unicamp; é autora de livro, capítulos de livros e artigos em revistas.

2 Dina Maria Martins Ferreira é professora e pesquisadora do Programa de PósGraduação em Linguística Aplicada, Universidade Estadual do Ceará/UECE. O primeiro pós-doutorado (2002-2003) no Instituto de Estudos da Linguagem, Unicamp; o segundo pós-doutorado pela Unicamp e pela Université Réné Descartes, Paris V, Sorbonne (2009-2010); doutorado pela UFRJ (1995); é autora de 5 livros, com vasta publicação em capítulos de livros e revistas nacionais e internacionais 


\section{RESUMO}

Este estudo se propõe a descontruir os limites conceituais de contexto. Partimos da Linguística Sistêmico-Funcional (LSF) de Halliday (1970; 1978), que não deixa de se pontuar na Análise de Discurso Crítica (ADC) (Fairclough, 2001) e utilizamo-nos de vozes da Filosofia da Linguagem (Wittgenstein, 1989) e da Pragmática (Austin, 1962), cujas interfaces caminham no contrafluxo dos dualismos entre o semântico como dimensão abstrato-formal e o pragmático como uma dimensão empírico-contextual. $E$, por uma estrada argumentativa, chega-se à impossibilidade de fixar categorizações conceituais (Rajagopalan, prelo), devido à fluidez em que o sentido de contexto se insere.

Palavras-chave: contexto; interfaces; fluidez conceitual.

\section{Considerando}

A primeira razão de estarmos, até hiperbolicamente, intitulando esse estudo sobre contexto como um percurso ad infinitum, senão ad nauseam, parte da perspectiva pragmática de que sujeitos são situados historicamente e considerados como e ao mesmo tempo singulares e sociais, em suas interações e práticas linguajeiras (cf. Nogueira de Alencar, 2010); e como tal, perguntamo-nos sobre prerrogativas teóricas que se arvoram de previsibilidades de sentido e seu contexto (Cf. Halliday, 1970, 1978). A segunda deve-se à busca de uma transdisciplinaridade, para alguns, e, multidisciplinaridade, para outros. Mostrar que estamos na transdisciplinaridade é arriscado, pois não estamos determinando nem um espaço teórico nem uma metodologia específica, ou melhor, não temos o objetivo de nos apropriar de teorias, tais como as referidas nesse texto, para modelar um novo quadro teórico independente. Fica mais coerente apontarmos para um percurso multidisciplinar, em que algumas áreas teóricas são levantadas para um fim desconstrutor e crítico (Derrida, 1973, 1991). E a terceira abraçaria as duas primeiras, pelo viés de uma prática científica analógica, não restrita ao disciplinar, mas, sim, ao temático - no caso o contexto -, cujo jogo analógico se faria ad infinitum. É como diz Boaventura de Souza Santos (2003: 66): “o conhecimento 
avança à medida que o seu objeto se amplia, ampliação que, como a da árvore, procede pela diferenciação e pelo alastramento das raízes em busca de novas e mais variadas interfaces".

Buscando nos inserir no "paradigma emergente" de uma prática científica (cf. Santos, 2003), visamos ao desafio de caminhar para além das posturas formalistas que prescrevem um ideal de interação entre um sujeito autônomo e o sentido por intenção (cf. Kant 1964, por exemplo), em prol de uma proposta de análise pragmática da vida cotidiana, via a crítica desconstrutora de Jacques Derrida (1991). Pela multidisciplinaridade e variadas interfaces, tais como a Linguística Sistêmico-Funcional (LSF) de Halliday (1970; 1978), que não deixa de se pontuar na Análise do Discurso Crítica (Fairclough, 2001) utilizamo-nos de vozes da Filosofia da Linguagem, Wittgenstein (1989), e da Pragmática, Austin (1962), que caminham no contrafluxo dos dualismos entre o semântico como dimensão abstrato-formal e o pragmático como uma dimensão empírico-contextual. Para Wittgenstein e Austin, o critério para a determinação do sentido está no próprio uso das palavras. Nessas duas vertentes, de visão antiessencialista, nos beneficiamos da crítica argumentativa de Derrida (1991) e a de Rajagopalan (prelo) em torno de uma noção fluída do que seja contexto, para reconhecermos os limites de algumas propostas conceituais, tendo em vista suas potencialidades a partir das práticas socioculturais contemporâneas.

Eis a proposta de um jogo analógico: desconstrução do conceito de contexto! Mas é importante salientar, até para não cairmos no paradoxo de fixar um limite contextual quando forçamos nossa argumentação para o não-limite de que "a desconstrução não consiste em passar de um conceito [contexto] para outro, mas em modificar e deslocar uma ordem conceitual assim como a ordem não-conceitual à qual se articula” (Derrida, 1991: 372).

3 Aliamos a LSF à ADC não no sentido de excluirmos as particularidades de cada teoria, mas porque nesse estudo essas duas teorias compartilham, de certa maneira, o aspecto crucial da noção de contexto. Conforme Fairclough (2003), os discursos são históricos e, destarte, só podem ser entendidos senão em referência a seus contextos. 


\section{No caminho da LSF}

Antes de apontar para as questões essencialistas do sentido de contexto pela Linguística Sistêmico-Funcional, importante incluir uma citação de Derrida, que direciona nosso questionamento sobre o aprisionamento do contexto ao protocolo do código:

A consequência desta insaciabilidade estrutural do contexto leva [...] 'à disrupção, em última análise, da autoridade do código como sistema fixo de regras; a destruição radical, no mesmo lance, de todo o contexto como protocolo de código (Derrida, 1991: 357; e citado em Kreinz, s/d: serial).

Nessa mesma direção, o filósofo alemão Rainer Piepmeier (1991) explica o pensamento derridiano ao dizer que "em Derrida o conceito de contexto não perde o sentido, mas passa a ser tido como 'jamais absolutamente determinável, possuidor de insaciabilidade estrutural'” (Piepmeier, 1991: 138).

Na Linguística Sistêmico-Funcional (LSF), Halliday (1978) propõe que a língua se organiza por redes relativamente independentes, redes essas a que chama de funções básicas da linguagem. E é na descrição dessas funções básicas que apontamos uma visão essencialista da parte desse autor, na medida em que pontua a questão de sistema: estruturas de texto, lexicogramática na função comunicativa da linguagem. Halliday (1978) oferece a função lógica da linguagem, como uma organização lógica de conteúdos, como se pudéssemos estruturar nossa experiência de mundo como instantâneos fotográficos que se fixam. Na sua proposta de linguagem e suas funções, apresenta a linguagem como tendo: (1) função representacional que codifica significados de nossa vivência e experiência de mundo; (2) função interpessoal que codifica interação e relações sociais; (3) função textual que codifica e os significados no desenvolvimento textual e organiza sua retórica. Enfim, em qualquer nível em que se estabeleçam as funções da linguagem, o termo "codificação" se faz continuamente marcado. E, se voltarmos à Linguística Tradicional (Geral ou Teórica, como assim o quiserem), o sentido de código se enclausura no de 
sistema, ou seja, um conjunto de sinais que se organiza por regras.

Por exemplo, temos no código da língua portuguesa 19 fonemas (Mattoso Câmara, 1942) que se organizam por regras; não adianta conhecer os sinais se não souber organizá-los, como também não resolve eu conhecer as regras se não conhecer os sinais. A noção de código fechado em um sistema é tão forte que até podemos fazer analogia com um aprendiz do sistema de informática, ou seja, não resolve eu saber que no teclado tem o "ctrl" e o "alt" se não souber as regras de combinações possíveis entre eles e com eles. Em ambos os patamares - sinais e regras -, a clausura e a previsibilidade se impõem, apesar da dita possibilidade de movimentação.

No que tange a prática de linguagem, Halliday (1970: 141) não deixa de dialogar com as vozes de Wittgenstein e Austin: "A natureza da língua(gem) está intimamente relacionada com as necessidades que lhe impomos, com as funções que deve servir. Estas funções, nos casos mais concretos, são específicas a uma cultura”. Mas o ponto de embaraço teórico, entre as duas vertentes, LSF e Pragmática, a nosso ver, está na noção de contexto, que para ambas é fundamental; a primeira conceitualiza a noção de contexto em perspectiva fronteirizante, e como tal essencialista, enquanto a Pragmática busca o descentramento dos limites fronteiriços. Nesse descentramento emerge o que se chama de uma "nova pragmática" (Rajagopalan, 1996, 2004, 2009, 2010; Mey, 1985, 1987, 2000, 2001), comprometida sócio-politicamente, contudo não se nega sua dívida com os pensadores funcionalistas e integracionistas britânicos (Malinowsky (1998[1922]; Firth, 1966 [1937]; Halliday, 1970; Harris, 1981).

Resumindo, para a LSF a noção de contexto é representada em dois níveis que são determinantes dos significados: o contexto de situação e o contexto cultural. Tal configuração de contexto em estratos vai permitir representar sua realização em níveis extralinguísticos e linguísticos na organização do sistema (Gouveia, 2009: 25). No contexto de situação, estabelecem-se: (1) campo - a ação social, o assunto sobre o que se fala, a natureza da ação; (2) relações - a estrutura de papeis, as pessoas e suas relações na situação de comunicação; (3) canal (fala e escrita) - organização simbólica e o modo retórico 
da linguagem. No contexto cultural, verifica-se o modo como usamos a linguagem para atingir os objetivos culturalmente apropriados, gêneros (Gouveia, 2009). Assim, o contexto, delimitado em dois níveis - nível contextual de situação e nível contextual de cultura -, passa a corresponder ao nível extralinguístico que se relaciona dialogicamente com o nível linguístico, ou seja, o estrato do contexto se realiza no do conteúdo, lembrando que este se estabelece no nível linguístico pela semântica (sistemas de significado), realizado na lexicogramática (sistemas fraseados, realizados, por sua vez, no nível da expressão fonologia, língua gestual e grafologia).

$\mathrm{O}$ que estamos questionando são as duas posições conceituais da LSF que parecem paradoxais entre si. De um lado, a LSF fornece um modus operandi acordante com a proposta de uma pragmática cultural e societal ao situar dialogicamente linguagem e sociedade, mas, de outro, usa a noção de contexto sob a égide de vertentes tradicionais, sem problematizá-la. Ou seja, parece justificar a noção de contexto aprioristicamente, reduzindo aspectos interacionais observáveis e demonstráveis. Um exemplo observável estaria em um diálogo em língua portuguesa entre um falante de Goa e outro do Brasil, congressistas de um Colóquio de Lusitanismo. Encontram-se no saguão do hotel, e o brasileiro, na "intenção" de manifestar polidez, pergunta: - Como vai você? Responde o goano: - A pé ou de carro? Para o brasileiro, o contexto comunicacional é o de saudar um colega, para o goano, sem negar a percepção de uma polidez deste colega, é um questionamento sobre o meio de como vai se locomover para o local do Colóquio. Os contextos cultural e situacional divergiram, desconectando sentidos que extravasaram por sobre o protocolo de código. Parece que o protocolo de código entrou em desajuste contextual da ordem do âmbito cultural e linguístico, ou seja, a motivação e a previsibilidade de sentido que a LSF postula - que a lexicogramática é determinada pelos usos e que os significados que se quer transmitir são fortemente dependentes dos contextos - caem por terra. Eis a prerrogativa da LSF: 
A relação entre a língua e os seus contextos de uso, ou dito de outra forma, a relação entre um texto e o seu contexto, é de tal forma motivada que, a partir de um contexto, será possível prever os significados que serão ativados e as características linguísticas potencias mais previsíveis para as codificar em texto (Gouveia, 2009: 25).

Podemos até aventar uma motivação em relação a um contexto, mas prever os significados parece não ser possível. Inclusive o brasileiro desse diálogo não pôde prever o contexto assimilado pelo goano e viceversa, nem o situacional imediato nem o cultural. Dessa forma, não

será possível deduzir o contexto em que o mesmo foi produzido, porquanto as características linguísticas selecionadas num contexto [não] codificarão dimensões contextuais, tanto do contexto de produção imediato situacional - quem diz o quê a quem, por exemplo -, como do contexto mais geral, cultural - que tarefa está o texto a desempenhar na cultura (cf. Eggins \& Martin, 1997: 236-237, citado em Gouveia, 2009).

E, nesse reducionismo, a noção de contexto da LSF não dá conta de uma organização de contexto relacionada à organização da gramática. Algemados se encontram contexto, uso, gramática e significado, o que nos leva à indagação se a LSF, no que tange à noção de contexto, não estaria fazendo parte das vertentes tradicionais do "contextualismo", definido como "a concepção de pragmática como extensão da semântica” (Souza Filho, 2006: 220), em que a simplificação e/ou a generalidade se fazem a ordem do momento.

\section{No contrafluxo da LSF}

Para poder justificar as divergências entre as vertentes da LSF e da Pragmática, no que concerne à noção de contexto, novamente nos dirigimos à crítica de Derrida (1991), cujos argumentos se fazem em "terapia" desconstrutora do sentido de contexto, tendo em vista a relação entre linguagem e sociedade. Derrida (1991) vai problematizar a noção de contexto partir da linguagem e de sua comunicabilidade. 
O autor enfatiza o equívoco de reduzir a comunicação aos limites do que se chama "contexto". Ele afirma que "um contexto nunca é absolutamente determinável, ou melhor, [...] que a sua determinação nunca é assegurada e saturada” (Derrida, 1971: 351).

Partimos da expressão derridiana "nunca é assegurada e saturada" para demonstrar a impossibilidade de conceitos, no caso, o do contexto, serem saturados e assegurados. E demonstramos uma controvérsia dentro de dois pilares da seara da linguística saussuriana: (1) língua é um sistema e (2) língua é dinâmica. Se o estruturalismo saussuriano diz que língua é sistema auto-suficiente, ao mesmo tempo postula sua dinamicidade e "evolução". No entanto, para que a língua se modifique em sua "evolução", não pode ser entendida como um sistema fechado. Pois como seus dados poderiam se movimentar? Esse tal sistema precisaria de resiliência, ou seja, espaço não preenchido para que os dados possam se movimentar. E nesses movimentos portas estão abertas, mesmo no que se chama de sistema. Logo não há sistemas fechados e como tal não são controláveis por suas regras autônomas e abstratas, sejam elas responsivas ao nível extra-linguístico ou propriamente ao linguístico. E diante desse argumento podemos aventar que "o que é transmitido, comunicado, não são fenômenos de sentido ou de significação" (Derrida, 1991: 349), protocolados no código.

Metaforizando a questão da resiliência com uma bola de futebol, de um lado, só consigo chutar uma bola se houver resilência de ar dentro dela (ausência de ar), de outro, preciso enchê-la de ar volta e meia (presença do ar) para que a ação do chute possa ser renovada. Controlo os dados do ar que entram e saem desse invólucro dito "sistêmico"? E pelo "sistema-de-ar-da-bola", diríamos que a saturação estrutural teria um duplo sentido (Derrida, 1991): (1) assinalar a insuficiência teórica do conceito de contexto, seja linguístico ou não-linguístico; e (2) tornar necessário um deslocamento do conceito. Fazendo analogia com o tal "sistema-de-ar-da-bola": na "insuficiência", o ar selecionado não é suficiente, logo as prerrogativas conceituais também não são saturadas; e, no "deslocamento", o movimento do ar em espaço não preenchido não pode ser precisado, logo conceitos não 
asseguram a totalidade do "espaço", pois se perdem em generalizações. Eis a natureza da resiliência: espaço incontrolável de medida, seja para delimitar o que falta, seja para avaliar o que há.

E relacionamos a resiliência na bola ao que Derrida (1991: 356) chama de "ausência de um destinatário”, ou seja, a comunicação "escrita” permanece legível não obstante o desaparecimento de qualquer destinatário determinável”. No nosso exemplo, os destinatários seriam os jogadores em interação lúdica; o sentido da expressão "chutar a bola” está ali realizando-se independente da ausência do jogador. O fato de não haver jogador não tira do "chutar a bola" a possibilidade de repetir o sentido ao mesmo tempo que o renova, sua natureza iterável (Derrida, 1991), haja vista o "chutar a bola" na civilização maia (honra da morte) e na dos brasileiros (honra da vitória). No contexto cultural, os maias faziam do jogo de futebol a busca pelo prêmio de morrer em nome dos deuses, os vencedores tinham a honra de se sacrificar em prol da aragem da terra; e no contexto cultural brasileiro é alegria e torcida, lágrimas e choros, tudo pela vaidade de vencer.

O que se viu é que o sentido de "chutar a bola" é reutilizado, mas não dependente de contextos nomeados como quesito apriorístico; o não quer dizer que o uso da linguagem não deixe os rastros em sua semeadura bustrofédica, na medida em que a linguagem é de natureza ecológica - em que nada se perde e tudo se aproveita. Seria o que Derrida (1999) chama de escritura bustrophédon, arado do boi, que se movimenta sem interrupção, da esquerda para direita e da direita para esquerda, ininterruptamente, ora revolvendo a terra nova da linguagem, ora levantando as terras mais antigas - linguagem aproveitada, re-aproveitada, resignificada, em sua natureza de iterabilidade.

É pela "ausência" que podemos lidar com a quebra radical do contexto (cf. Derrida, 1991: 355) para efetivação do sentido, ou seja, preciso da ausência para reconhecer pelo menos algum vestígio, alguma especificidade de sentido. Se na comunicação escrita eu precisasse de um destinatário para que o sentido se realizasse, a comunicação perderia o seu papel, ela não poderia ser repetível e renovada. A 
comunicação e seu sentido para ser o que é não pode precisar de um destinatário, de uma interlocução concreta, senão a própria escrita ou qualquer comunicação, seja em que tipologia de código, perderia a sua razão de ser. Logo é na ausência que a iterabilidade se dá o direito de manifestação.

Mas, quando utilizamos a expressão derridiana "comunicação escrita”, poderia o leitor se perguntar se estamos argumentando apenas pela base de uma comunicação escrita, enquanto a LSF se situa na língua (fala e escrita). Primeiro queremos deixar claro que não nos interessa a dicotomia hierárquica entre fala e escrita, postulada pela linguística tradicional, segundo, quando abordamos "comunicação escrita", não estamos descartando todo e qualquer tipo de comunicação que, porventura, algumas tipologias possam fronteirizar:

Os traços que se podem reconhecer no conceito de escrita são generalizáveis. Eles valeriam não só para todas as ordens de 'signos' e para todas as linguagens em geral, mas também, para além da comunicação semio-linguística, para todo o campo que a filosofia chamaria de experiência, mesmo a experiência do 'ser', a dita 'presença' (Derrida, 1991: 358) (grifo nosso).

$\mathrm{O}$ argumento mais forte em detrimento a uma noção de contexto vinculada à previsibilidade semântica está na iterabilidade (Derrida, 1999; 1991), porquanto a disrupção da linguagem quebra com a autoridade do código, como um sistema finito de regras e autosuficientes, inclusive excluindo o contexto como um condicionador essencialista do sentido. Se todo sentido é fixo a seu contexto, ele ali termina, sem que a linguagem assuma a sua iterabilidade - iter e itera -, já que ele pode ser continuamente repetido e renovado. Aí a grande razão da comunicabilidade e seu sentido: "A possibilidade de repetir, e, portanto, identificar as marcas está implícita em qualquer código, fazendo deste uma grelha comunicável, transmissível, decifrável, iterável por um terceiro, depois por qualquer outro utente possível em geral" (Derrida, 1991: 356). 


\section{3. "Contextualismo": várias vozes}

O questionamento sobre a noção de contexto tem suas marcas argumentativas na crítica de Derrida a Austin (Austin, 1962; Derrida, 1991), quando afirma que Austin não percebeu a iterabilidade do ato de fala no que tange ao ato locucionário e que o contexto não pode ser "exautivamente determinável". Ou seja, diante da lista de "infelicidades" de performativos, o sujeito comunicante retorna sempre ao seu contexto primeiro, fazendo desse sujeito sempre um comunicante intencional: "o acontecimento do performativo regressa[ria] a um elemento que Austin chama de o contexto total" (Derrida, 1991: 364). Para Derrida, Austin se detém na convencionalidade que forma a circunstância (corresponderia ao contexto situacional e cultural da LSF) do enunciado, com isso trazendo para dentro da noção de contexto o caráter de convencionalidade. Butler (1977) também entra nessa discussão ao reinterpretar o conceito de "iterabilidade" de Derrida, postulando sobre a impossibilidade de termos o controle sobre os efeitos do performativo, na medida em que não podemos impedir o excesso de significação e de possibilidade de repetição. Diz a autora que, em cada ato de fala, se estabelece uma "história" que pode ser negociada e subvertida.

E, também nessa problemática de contexto protocolado no código, Wittgenstein (1989) apresenta outro ponto de vista a partir da ideia de "jogos de linguagem". Para Wittgenstein, a linguagem está submersa em uma "forma de vida", e, como tal, sujeita às singularidades e particularidades das atividades humanas, ou melhor, a linguagem não diria respeito à realidade que nos cerca, mas à sua maior ou menor utilidade em seu poder explanatório. Fora do uso de linguagem, não haveria linguagem, e, portanto, a noção de contexto não caberia em um contexto total (Austin, 1962), nem por sua gramática, já que contexto e gramática só se tornariam evidentes no uso da língua(gem). A proposta da "gramática" wittgensteiniana não nega uma linguagem historicamente situada, constituída e constitutiva de jogos culturais, nem o excesso de significação e sua iterabilidade, mas alarga seu sentido pela proposta de que abriga a possibilidade de 
novas formas de vida, novos jogos, com múltiplas agências de sujeitos com novos usos de sentidos. Esse autor advoga que o que determina uma regra, se houve repetição, não é nem a intenção do falante, nem uma descrição exaustiva do significado, mas, sim, a convenção social e sua historicidade.

\section{Ponderações}

Diante de tantas vozes e caminhos que parecem divergentes, não nos perguntamos como situar a linguagem sem delimitar o contexto. Como diz Rajagopalan (prelo), "a questão do contexto é muito mais complicada do que a forma casual com que muitos estudiosos a tratam. Apelar para o contexto é uma coisa, dizer com precisão qual é o contexto é, no fundo, simplesmente impossível”. Nem Halliday, nem Derrida, nem Butler, nem Austin, nem Wittgenstein eliminaram o conceito de contexto, mas Rajagopalan nos coloca na arapuca insolúvel de que sempre estaremos em busca do próprio:

O contexto não é, ao contrário do que muita gente pensa, um adendo, um acréscimo a um 'dado' previamente identificado e cuja existência está garantida ontológica e epistemologicamente. O contexto, uma vez reconhecido, acaba se mesclando ao "dado" para transformar em um dado novo, mais 'realista'. Mas isso jamais pode ser o fim da linha, pois o novo amálgama que acaba de despontar, a saber 'dado-mais-seucontexto imediato' suscita, ou melhor dizendo, nos obriga a uma nova procura de contexto [...] Qualquer enunciado está inserido em um contexto maior. Só que o tal do contexto que imaginamos inicialmente não exaure toda a questão do contexto [...] Isso porque, uma vez delineado o contexto imediato, resta delinear um novo contexto para aquilo que já é um outro enunciado, a saber, o enunciado-inserido-noseu-contexto. Ad infinitum. Ad nauseam.

Nesse ad infintum, propositadamente utilizado em nosso título, manifesta-se o lamento de um desejo de não alcançar a total transparência: 
A tese do representacionalismo é, ao mesmo tempo, uma lamentação e uma expressão de desejo. Ela é um gesto de lamentação porque afirma a incapacidade dos seres humanos de apreenderem o mundo ${ }^{4}$ tal e numenal qual [...] Por outro lado, ela também é uma expressão de um esejo, pois ele age como condição ideal [...] a total transparência (Rajagopalan, 2003: 31).

Mas ainda bem que a voz de Nietzche se faz pela de Rajagopalan (prelo), ao nos mostrar que o "diálogo entre o passado e o presente é inevitavelmente infindável” - à qual nos juntamos pela afirmação de que somos alimentados pela hybris ${ }^{5}$ da busca incessante -, e Rajagopalan nos consola ao dizer que "isso não é motivo de desespero, pelo contrário, e isso que torna a pesquisa histórica uma atividade tão excitante!”

Recebido em: dezembro de 2012

Aprovado em: fevereiro de 2012 dinaferreira@terra.com.b claunoce@yahoo.com.br

\section{Referências bibliográficas}

AUSTIN, J. How to do things with words. Cambridge: Harvard University Press, 1962.

BUTLER, J. Excitable speech: a politics of the performative. New York: Routledge, 1997.

DERRIDA, J. Gramatologia. (Trad. Miriam Chainderman e Renato Janine Ribeiro). São Paulo: Perspectiva, 1973.

4 númeno, noumenon (voov́ $4 \varepsilon v o v$ ), termo introduzido por Kant para indicar o objeto do conhecimento puro, que é a coisa em si.

5 Hybris, transliterado do grego, é uma expressão que indica um impulso exacerbado, que de tão forte e arraigado não é possível controlá-lo, a ele estamos aprisionados pelo querer algo infinitamente. 
. Assinatura, acontecimento, contexto. In: Derrida, J. Margens da filosofia (Trad. Joaquim Torres Costa e António M. Magalhães). São Paulo: Papirus, 1991, p. 349-373.

EGGINS, S. \& Martin, J. R. Genres and registers of discourse. In: Van Dijk,T. A. (Ed.) Discourse studies: a multidisciplinary introduction. V. 1 - Discourse as structure and process. London: Sage Publications, 1997, p. 230-256.

FAIRCLOUGH, N. Discurso e mudança social. (Org. da trad. Izabel Magalhães) Brasília: Universidade de Brasília, 2001.

. El análisis crítico del discurso como método para la investigación en ciencias sociales. In: Wodak, Ruth; Meyer, Michel (Eds.). Métodos de análisis crítico del discurso. (Trad. Michel Lahud e Yara Frateschi Vieira). Barcelona: Gedisa, 2003, p. 179-203.

FIRTH, J. R. Context of situation. In: . The tongues of men \& speech. Oxford: Oxford University Press, 1966[1937], p. 110-114.

GOUVEIA, C. A. M. Texto e gramática: uma introdução à linguística sistêmico-funcional. Revista Matraga. Rio de Janeiro, 16, 24: 13-47, 2009.

HALLIDAY, M. A. K. Language structure and language function. In: Lyons, J. (Ed.) New horizons in linguistics. Harmondsworth: Penguin Books, 1970, p.140-164.

. Language as social semiotic: the social interpretation of language and meaning. London: Edward Arnold, 1978.

HARRIS, R. The language myth. London: Duckworth, 1981.

KANT. I. Fundamentação da metafísica dos costumes (Trad. Antônio Pinto de Carvalho). São Paulo: Companhia Editorial Nacional, 1964.

KREINZ, G. Comunicação: o mundo movente de Jacques Derrida. Revista Existo. s/d. www.revista exito.com.br; acesso em outubro de 2010.

MALINOWSKI, B. Argonautas do Pacífico Ocidental. Os Pensadores. São Paulo: Abril Cultural, 1998 [1922].

MATTOSO CÂMARA JR., J. Princípios de linguística geral. Rio de Janeiro: Padrão, 1942.

MEY, J. L. Whose language: a study in linguistic pragmatics. Amsterdam: John Benjamins, 1985.

- Poet and peasant: a pragmatic comedy in five acts. Journal of pragmatics. 11: 281-297, 1987. 
. When voices clash: a study in linguistic pragmatics. Berlin: Mouton de Gruyter, 2000.

. Pragmatics: an introduction. Oxford: Blackwell, 2001.

NOGUEIRA de Alencar, C. Violência em jogos de linguagem. Anais do I Fórum Nacional sobre Representação Conceitual e Categorização: conceitualização de violência , UFC, serial, 2010.

PIEPMEIER, R. Finis hominis? Filosofias pós-modernas e a questão da ciência e da técnica. (Trad. apostilada de Ciro Marcondes). Munique: Milhelm Fink, 1991, p.132-140.

RAJAGOPAlAN, K. Pragmática - uma vista aérea. Cadernos de Estudos Linguísticos. 30: 5-7, 1996.

. John R. Searle (1932- ). In: Strazny, P. (Org.). Encyclopedia of Linguistics. V. 2.

New York, EUA: Fitzray Dearborn, 2004, p. 936-938.

. Pragmatics today: from a component of linguistics to a perspective of language - a tribute to Jacob Mey. In: Turner, K. e Fraser, B. (Orgs.). Language in life, a life in language. Jacob Mey - a festschrift. London: Emerald Group Publishing Limited, 2009, p. 335-341.

. A Nova Pragmática - Fases e Feições de um Fazer. São Paulo: Parábola, 2010.

. A "dadidade" dos ditos dados na/da pragmática. In: Gonçalves, Adair (Org.). Linguística e as várias vertentes: como fazer pesquisa na área da linguagem. (prelo)

SOUZA FILHO, D. M. A teoria dos atos de fala como concepção pragmática da linguagem. Filosofia Unisinos. 7. 3: 217-230, 2006; disponível em http://www.unisinos.br/publicacoes_cientificas/images/stories/pdfs filosofia/vol7n3/art01_marcondes.pdf ; acesso em 15 de maio de 2010.

SANTOS, B. de S. Um discurso sobre as ciências na transição para uma ciência pós-moderna. São Paulo: Cortez, 2003.

WITTGENSTEIN, L. Investigações Filosóficas. Os Pensadores (Trad. de José Carlos Bruini). São Paulo: Nova Cultural, 1989. 
